\title{
POÉTICAS DA ANIMALIDADE NAS ARTES VISUAIS E NA LITERATURA: POTÊNCIAS ESTÉTICAS PARA OUTRAS RELAÇÕES DE ALTERIDADE NA EDUCAÇÃO
}

\author{
ANIMALITY POÉTICS IN VISUAL ARTS AND LITERATURE: \\ POTENTIAL FOR OTHERS RELATIONS OF ALTERITY IN EDUCATION
}

\author{
Tathiana Jaeger de Morais \\ Mestre em Educação, Universidade Federal do Rio Grande do Sul - UFRGS \\ Porto Alegre, Rio Grande do Sul - Brasil. \\ tathij@gmail.com \\ Luciana Gruppelli Loponte \\ Doutora em Educação, Universidade Federal do Rio Grande do Sul - UFRGS \\ Porto Alegre, Rio Grande do Sul - Brasil. \\ luciana.loponte@ufrgs.br
}

Resumo: Este artigo apresenta relações entre animalidade, artes visuais e literatura como potência para pensarmos outras relações de alteridade na educação, a partir de um diálogo entre os campos da arte e da literatura que desacomodam certas verdades sobre como relacionamonos com os outros, animais humanos ou não. Tais enlaces estão ligados ao conceito de Poéticas da Animalidade, que irá dar forma e vida a um diálogo entre as provocações ético-estéticas de certas obras da artista visual Ana Teresa Barboza e da escritora Clarice Lispector. Para desenvolver esta pesquisa em educação em conversa com o campo das artes visuais e da literatura, assumimos como parceiros teóricos Derrida (2002; 2004; 2016) e Skliar (2014).

Palavras-chave: Animalidade. Alteridade. Artes visuais. Literatura. Educação.

Abstract: This article presents relations between animals, visual arts and literature as a power to think about other relations of alterity in education, based on a dialogue between fields of art and literature that discomfort certain truths about how to relate to other human animals or not. These items are linked to the concept of Animality Poétics, which will give shape and life to a dialog between ethical-aesthetical provocations of certain works from the visual artist Ana Teresa Barboza, as well as in writter Clarice Lispector's work. In order to develop this research in education that talks to the field of visual arts and literature, Derrida $(2002 ; 2004 ; 2016)$ and Skliar (2014) are theoretical partners.

Keywords: Animality. Alterity. Visual arts. Literature. Education.

\section{Para citar - (ABNT NBR 6023:2018)}

MORAIS, Tathiana Jaeger de; LOPONTE, Luciana Gruppelli. Poéticas da animalidade nas artes visuais e na literatura: potências estéticas para outras relações de alteridade na educação. Eccos - Revista Cientifica, São Paulo, n. 53, p. 1-18, e16862, abr./jun. 2020. Disponível em: https://doi.org/10.5585/eccos.n53.16862. 


\section{Animalidade, estética e educação: uma breve introdução}

"A certeza de que dou para o mal, pensava Joana. O que seria então aquela sensação de força contida, pronta para rebentar em violência, aquela sede de empregá-la de olhos fechados, inteira, com a segurança refletida de uma fera? [...] Sentia dentro de mim um animal perfeito, cheio de inconsequências, de egoísmo e vitalidade.

Sim, ela sentia dentro de si um animal perfeito. Repugnava-lhe deixar um dia esse animal solto. Por medo talvez da falta de estética. Ou receio de alguma revelação [...]." (LISPECTOR, 1998, p.18).

Imagem 1 - Ana Teresa Barboza. (sem título), 2011, da série Animales familiares. Grafite e Bordado em Tela (104 x 102)

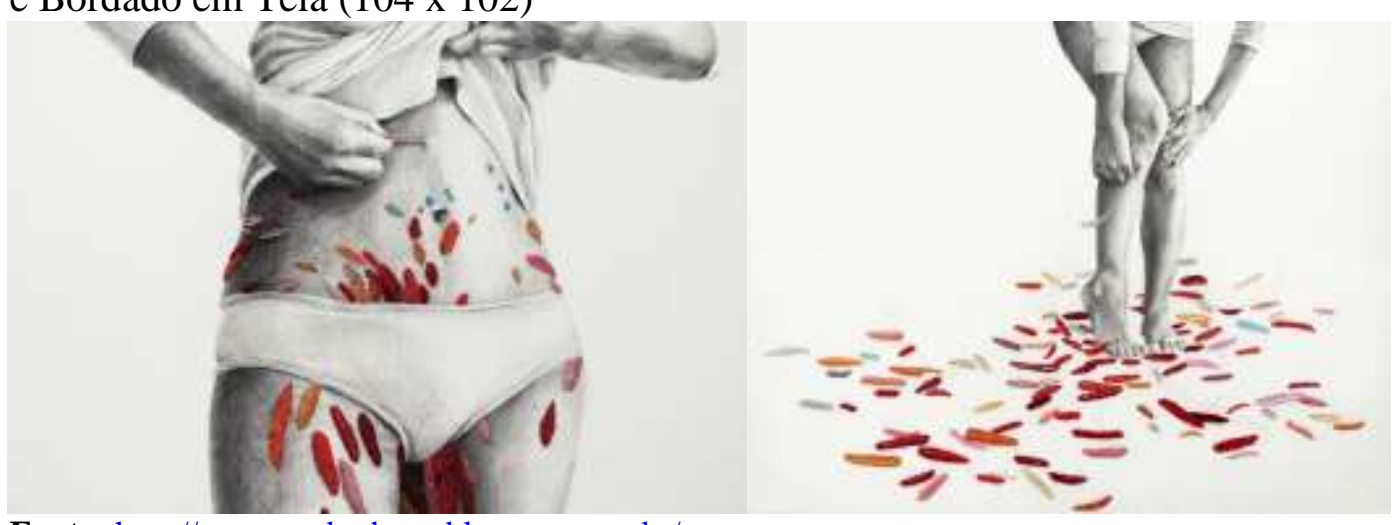

Fonte: http://anateresabarboza.blogspot.com.br/

Joana, personagem do romance Perto do coração selvagem (1998), de Clarice Lispector, sentia, dentro de seu corpo, um animal perfeito, uma fera, na qual pulsavam múltiplos instintos e afetos, mas que a personagem mantinha presos dentro de si. Joana acreditava inicialmente que, por deixar habitar essa fera dentro de seu corpo, algo de ruim criava-se em seu íntimo. A personagem teme a fera que a habita, esse lado animal onde pulsam sentidos e afetos, mas ao mesmo tempo deseja-a e sente-se atraída por ela. A relação que a personagem estabelece com a animalidade e os animais é dividida em polaridades ambíguas, ora representam a maldade, a violência que deve ser domesticada e abafada, ora aparecem como potência de vida, como pulsação e manifestação de um pensamento que perpassa o corpo, os sentidos. Nessa dualidade, Joana teme entregar-se a essa animalidade que aprisiona, uma animalidade que, mesmo negada, não deixa de habitar seu corpo, o qual parece criar-se a partir de um certo tipo de normatização de humano, em que a animalidade não é bem-vinda e deve ser abafada, domesticada.

A partir da personagem Joana (LISPECTOR, 1998), podemos estabelecer uma conversa com a obra de Ana Teresa Barboza, da série Animales Familiares, sem título (Imagem 1). Na obra, uma humana arranca de seu corpo o que parece ser os vestígios aparentes da animalidade 
que a habita. Mutila a si própria para enquadrar-se no mesmo modelo de humano que aprisiona Joana. Humanidade e Animalidade coexistem em ambas as personagens numa relação dúbia e mutável. Na obra de Barboza (Imagem 1), a animalidade parece-nos também representar a potência e pulsão de vida. O corpo humano é cinza, frio e sem vida, porém as penas que arranca dele são coloridas, cheias de cor, de vida e de detalhes. Contudo, inicialmente as duas personagens acreditam que sua animalidade torna-as menos humanas aos olhos de certas normatizações de humano. As personagens, assim como nós, humanos, carregam, em sua herança, um modelo formativo moderno e também cristão, que as dividiu em dicotomias, sendo que a primeira - e o ponto inicial dessa formação - é a divisão entre humanidade e animalidade, e, depois, no mesmo âmbito, a relação entre razão e sensibilidade. Nesse modelo de formação, não existe espaço para o estranho, o diferente, a arte e muito menos para a experiência estética. Neste artigo, apostamos, num modo de formação alargado pelas contaminações da arte e da estética, implicando formas plurais de reinventarmos ser humanos e relacionarmo-nos com a outridade. Nessa esteira, buscamos contribuir para ampliar as noções de arte e estética no campo da educação, como forma de pensamento que alarga modos de ética, de vida e política, bem como do que entendemos por animalidade e suas relações com a alteridade e a educação.

Em nossa cultura ocidental, as concepções sobre a animalidade foram construídas, em sua maioria, em oposição à humanidade, configurando um lugar de conceitos que dificilmente se esgotariam de significados, e que não tentaremos delinear com precisão neste artigo, mas multiplicá-los. A animalidade carrega, historicamente e ainda hoje, a marcação e a denominação do não ser, do irracional, amoral, anormal, selvagem, bárbaro e da besta, sendo sinalizada moralmente como um lugar de paixões brutas, instintos, violência, loucura, luxúria e excessos (FOUCAULT, 2009; MACIEL, 2016). Tensões, oposições e negações fizeram parte da produção do que entendemos hoje por humano, um ser de existência singular que pertence ao conjunto da humanidade somente quando consegue cortar a ligação com o animal e domar a enigmática e assustadora animalidade que o habita. Esse modelo de humano ideal, apto a adentrar no conjunto da humanidade, foi pensado por certas visões teológicas, filosóficas e pedagógicas, como um ser singular, uno e soberano a outras formas de vida, num movimento de transcendência, oposição e negação.

Fomos ensinados a entender a animalidade sempre em oposição ao que seria próprio do ser humano. Ao sermos provocados com outras leituras possíveis sobre a animalidade, podemos ficar confusos ou perdidos. Essa provocação desmobiliza também as construções baseadas em binarismos que movimentaram a filosofia moderna: razão/sensibilidade; homem/mulher; cultura/natureza; humano/animal, só para citar algumas. Nessas dicotomias binárias, 
negligenciamos e subestimamos os outros humanos que não são vistos como semelhantes e os animais, mas também a nós mesmos, quando desqualificamos nossos corpos, desejos, afetos, instintos em detrimento da razão. A animalidade é supostamente o lugar desses sentidos desqualificados, o lugar dos animais e dos outros humanos, supostamente mais "animalizados": o louco, o negro, o índio, a mulher, o deficiente, o pobre, o selvagem, o homossexual e tantos outros que não se enquadram nesse modelo ideal de humano.

Nesse mesmo caminho, a pedagogia moderna, ligada a certas visões humanistas, exclui a animalidade e sua carga de instintos, sensibilidades e afetos do processo formativo. Para tal modelo, a escola é o lugar de formarmo-nos humanos ideais, lugar de civilizar, socializar e educar uma criança para conseguir ascender ao suposto conjunto soberano que é a Humanidade. Um processo de formação que abre caminhos para massacres, encarceramentos e domesticações de todos os outros viventes que não seguem esse padrão de normalidade, de mesmice. Estamos tratando aqui de qualquer outro, humano e animal, que não siga os modelos transcendentais, racionais e puramente científicos dessas visões, que inventaram um humano dividido em sua condição biológica de animal e sua condição de ser humano. Essa herança perpetua um modo de relação com outros, em que esses seres não têm a permissão de se constituírem como alteridades, pois o outro é entendido como um mesmo, como um próximo ao eu, que pode ser compreendido e assimilado. Esse modelo de educação moderna ainda permeia as práticas docentes e a cada dia parece ressurgir com novas propostas, que negam e excluem o diferente, não nos deixando ver e ser vistos por esses outros que permeiam a escola e a vida. Tal modelo também nega as possibilidades formativas da arte. Por tais motivos, acreditamos que problematizar as relações entre animalidade, alteridade, artes visuais e literatura dentro do campo da educação é uma questão política e ética, em que está em jogo a vida de seres dotados de alteridades que não se encaixam nos modelos universais, sejam eles animais, homossexuais, mulheres, índios, negros, crianças e os tantos outros que foram dotados historicamente de uma "maior animalidade".

Nessa direção, buscamos, neste artigo, pensar outras relações de alteridade na educação, que se expandam para além de conceitos engessados de gênero, raça, classe social ou espécie. Esse pensamento é movimentado a partir de um diálogo entre certas práticas artísticas e literárias aliadas ao conceito de poéticas da animalidade ${ }^{1}$, que é pensado, neste trabalho, como uma potência estética e política que nos provoca e educa mediante outras racionalidades, sensibilidades e linguagens. Nesse caminho, teremos, como parceiros teóricos, o pensamento de Derrida (2002;2004;2016) e Skliar (2014). Tomaremos, como materialidades de análise, as provocações ético-estéticas de certas obras da artista visual Ana Teresa Barboza e da escritora Clarice Lispector. A partir dessas produções estéticas, a animalidade é problematizada como 
uma potência política e ética para a educação que nos guia a pensar pluralmente os outros e a nós mesmos.

\section{Poéticas da animalidade: artes visuais, literatura e outras relações de alteridade na educação}

A partir da crise do humanismo e sua crítica por filósofos como Althusser e Foucault, a mudança de lugar do animal no plano teórico, a emergência da questão animal motivada por pesquisas do campo da etologia e ecologia (PRIKLADNICKI, 2015, p. 19-20), começam a surgir inúmeras pesquisas referentes ao tema da questão animal ${ }^{2}$, em diferentes campos do saber e assumindo diferentes correntes de pensamento ${ }^{3}$. Nessa esteira, chegamos ao termo poéticas da animalidade num movimento de pensar de outros modos nossa animalidade e nossa relação com as alteridades humanas e animais e ao mesmo tempo aproximar-nos de outras sensibilidades para pensar essas questões na educação. $O$ termo já foi utilizado antes, pelo menos, em três capítulos de livros e numa dissertação de mestrado em Letras. Em nossa leitura do termo poéticas da animalidade, as poéticas seriam uma via de acesso "a outra margem", rumo à pele da animalidade, que, por sua vez, seria um espaço de relação entre alteridades, por meio de uma conversa ético-estética entre certas obras visuais e literárias, entendidas como multiplicadoras de possibilidades éticas, estéticas e políticas de relação conosco e com outras formas de vida. As poéticas da animalidade são poéticas dos outros enquanto alteridades radicais, singularidades irredutíveis, mas também dos outros que habitam em nós. São poéticas da diferença e não do diferente. Poéticas políticas e filosóficas, poéticas pedagógicas, mas não pedagogizantes.

As poéticas da animalidade estão num contexto de produções estéticas que buscam outros ordenamentos e saberes das relações entre humano e animal, animalidade e humanidade, que, ao serem investigados, fazem o animal e a animalidade mudarem de lugar na nossa cultura ocidental (GIORGI, 2016). Mediante essas produções, animalidade e animal assumem outros lugares em nossa cultura e não mais se encontram, como costumamos ver nas artes visuais e na literatura, pela via de metáforas, fábulas e linguagens figurativas. A animalidade e o animal modificam-se por meio de uma criação poética da animalidade que não nega sua singularidade e sua relação sensível, ética e política com o humano e a humanidade. Tais produções, como algumas que apresentamos neste artigo, reinscrevem outros saberes em torno do humano e do próprio animal, colocando-os em contágio e relação, multiplicando, desse modo, seus sentidos. Assim, as práticas artísticas e literárias pensadas a partir do conceito de poéticas da animalidade colocam-nos em suspensão, movimentam nossas posições de sujeitos ligados a uma certa 
construção humanista antropocêntrica, bem como nossas relações com outras formas de vida e conosco mesmo.

Na primeira parte deste artigo, aproximamo-nos da personagem Joana (LISPECTOR, 1998) e, junto dela, iremos abrir alguns caminhos para pensarmos as relações entre animalidade, alteridade, artes visuais, literatura e educação. Joana era sóbria, mas, dentro dela, borbulhava uma força vermelha e brutal, uma "coisa", e, quando permitia entregar-se a essas sensações e percepções orgânicas, acessava um outro ser que a habitava: "um animal perfeito, cheio de inconsequências, de egoísmo e vitalidade" (LISPECTOR, 1998, p. 18), deslocando para o corpo, para a animalidade, os modos de saber antes sustentados somente pela e na razão. A partir de uma racionalidade sensível e estética, ela experenciava a vida pulsante que a habitava e não fazia distinções entre si mesma, outros animais e a natureza. Porém, Joana tratava essas percepções como algo ruim, como o gosto do mal e não aceitava encharcar-se da beleza e força desse animal perfeito que estava preso a ela e permitia-lhe sentir e ser outros em um só. Assim, por boa parte de sua vida, continuava a viver sendo somente a Joana racional e domesticada que vivia livre apenas em seus pensamentos, uma humana que negava suas pulsões, seus afetos, suas emoções encarnadas nesse animal perfeito, nessa animalidade, "nesse bicho que adestrou suas passadas para caber dentro da jaula", uma jaula feita por homens, desde que ela era mulher (LISPECTOR, 1998, p. 190).

Porém, Joana mostra-nos que a animalidade que vive em nós, mesmo abafada, não nos abandona. Nós, humanos, não somos obrigados a seguir o próprio começo (LISPECTOR, 1998, p.196), não precisamos seguir acreditando em linhas únicas e precisas que separam os humanos dos animais e de sua própria animalidade. Mas podemos, quem sabe, aprender com o movimento de Joana ao final do livro, em que vislumbra entregar-se completamente a animalidade que a habita, partir de outros saberes, sentidos e sensibilidades. Nesse ponto, Joana diz que será forte como a alma de um animal e que, de qualquer luta ou descanso, se levantará forte e bela como um cavalo (LISPECTOR, 1998, p. 200-202). É uma entrega, uma abertura que implica algumas lutas, pois inverte a lógica humanista antropocêntrica e cartesiana sobre ser humana, bem como o sentido das normatizações sobre ser mulher. São lutas que a personagem irá travar forte e bela como um cavalo novo, potência que se cria mediante essa entrega de experimentar a animalidade que habita o seu corpo. Nessa experiência, a personagem faz outras de si mesma, nos mostrando caminhos de uma formação criativa e sensível que parte da animalidade e suas pulsões.

Acreditamos que, para seguir os passos de Joana e com eles abrir novos caminhos formativos que possibilitem outras relações de alteridade na educação, é necessário um salto à 
experiência poética e estética da animalidade para estranhar as imagens e as palavras excessivamente humanas, para estranhar nosso próprio pensamento racional e cartesiano, que nos afasta de outras possibilidades de ser e pensar. Nesse paradoxo, encontra-se a diferença entre a filosofia e a poesia de que trata Derrida (2002, p. 22), pois esta última vai na direção contrária, conduzida pelos poetas e artistas que se permitem ser "assombrados e atraídos, ao mesmo tempo, pela estranheza animal - são aqueles que podem dar o salto à outra margem e entrar nas esferas da alteridade animal, dela extraindo um saber possível" (MACIEL, 2016, p. 100). Nesse "salto à outra margem", nessa travessia entre fronteiras, nessa entrega e no desassossego de habitar nossa animalidade, analisaremos as provocações ético-estéticas das obras escolhidas, a partir de uma "responsabilidade incondicional" (DERRIDA, 2002, 2004, 2016) com nossa própria animalidade e a dos animais. Esse "salto à outra margem" seria, desse modo, uma operação analítica responsável, mas também uma provocação a quem lê este trabalho, para, talvez, ser outros e não simplesmente estar na pele desses outros.

Para realizarmos essa operação, chegamos ao termo poéticas da animalidade num movimento de pensar de outros modos nossa animalidade e nossa relação com as alteridades humanas e animais e ao mesmo tempo aproximar-nos de outras sensibilidades para pensar essas questões na educação. Essa operação analítica responsável será movimentada pela criação de um diálogo ético-estético certas obras das artistas Ana Tereza Barbosa e Clarice Lispector, aliada ao conceito de poéticas da animalidade. Acreditamos que essas produções podem expandir o que entendemos por animalidade e alteridade na educação. Pois, elas provocam-nos a estabelecer outras relações com a animalidade que nos habita, diferentes das construídas pela nossa herança da teologia e da filosofia humanista antropocêntrica, ou seja, são obras que, de alguma forma, suspendem nossas verdades e nossa herança. Além disso, também exploram um certo medo, um desassossego ou tensões de nos entregarmos à animalidade.

Para iniciar o diálogo e a análise das obras, voltaremos, mais uma vez, à Joana (LISPECTOR, 1998). A personagem mostra-nos que parece ser necessário perder um certo medo de entregar-se à animalidade, a outras racionalidades e ao estranho, para entregar-se à diferença e multiplicidade que nos habita - é preciso transpor um abismo de tensões, desassossegos e potências. Para explorar tal movimento, escolhemos obras que embaralham as supostas fronteiras entre o que é próprio do animal e do humano, do eu e dos outros. Acreditamos que essas obras convidam-nos a uma experiência de modificação do eu pelo contato com a animalidade e com o outro, bem como a um movimento que imprecisa a suposta linha instransponível entre humanos e animais e indica-nos que nessas bordas vivem múltiplos seres dotados de singularidade, de alteridade. Vimos esse movimento com Derrida (2002, p.57), 
sob a denominação de "uma outra lógica do limite", que não busca apagar os limites entre humanos e animais, mas os multiplica a fim de torná-los imprecisos.

Podemos aproximar-nos dessa experiência de limitrofia (DERRIDA, 2002, p. 57), que questiona os limites dos "próprios do homem” criados pelos discursos teológicos e filosóficos antropocêntricos, a partir do conto Tentação de Clarice Lispector (1987), que se encontra também em outro livro da autora, com o provocativo título O intransponível (LISPECTOR, 1999). A história é narrada por uma terceira pessoa, que presencia e parece envolver-se também em uma experiência-limite entre uma menina ruiva e um cão basset, ruivo também. Essa narradora (ou narrador) conta-nos o que parece ser uma cena simples e sem nexo que viveu em seu cotidiano, mas que, aos poucos, mostra-nos ser uma cena poética e cheia de revelações vividas entre seres solitários, singulares e supostamente opostos que, pelo olhar, sensibilidade e outras formas de comunicação, transpassam os limites do eu e do outro, do humano e do animal. A menina ruiva tinha um olhar submisso e paciente; o sol escaldante flamejava em sua cabeça enquanto ela soluçava e agarrava-se a um objeto que a salvava daquele estado, uma bolsa velha de alças partidas, que segurava "com um amor conjugal já habituado". É nessa pintura pitoresca e peculiar que a narradora (ou o narrador) e a menina percebem-se e olhamse, sem palavras, “desalento contra desalento" (LISPECTOR, 1987, p. 59). Essa melancolia é quebrada pela chegada de um cão acompanhado por sua dona. A narradora (ou o narrador) diz que ele era a outra metade dessa menina ruiva, marcada por sua diferença, pois "numa terra de morenos, ser ruivo era uma revolta involuntária" (LISPECTOR, 1987, p. 59). Seu irmão encarnado na figura de um cão, era um basset ruivo também, lindo e miserável, "doce sob sua fatalidade" (LISPECTOR, 1987, p. 59). Que fatalidade? Não ser humano? Estar humanizado? $\mathrm{Ou}$ ser ruivo? Os dois ruivos de pelos curtos e vermelhos olhavam-se profundamente, entregavam-se em uma comunicação sem palavras e gestos, apenas pelo olhar. O que se disseram nem nós nem a narradora (ou o narrador) sabe, sabemos apenas que se comunicaram e, sem palavras, eles pediram-se, com urgência, encabulados e surpreendidos (LISPECTOR, 1987, p. 60). O que suspeitamos é que, nesse encontro de olhares, os dois suspenderam-se e permitiram-se, pelas suas diferenças e semelhanças, um contágio, um estranhamento que os levou além dos limites do outro, por poucos segundos, pois “ambos eram comprometidos. Ela com sua infância impossível [...]. Ele com sua natureza aprisionada." (LISPECTOR, 1987, p. 60). Essas três alteridades deixaram-se ser vistas e questionadas pelo olhar do outro. Mas o que será que viram? Certezas não temos, mas podemos ao menos deixar-nos ser invadidos por essa experiência poética e criar teses: talvez o cão tenha visto na menina ruiva a animalidade que nela habitava, ou, quem sabe, tenha visto nela um espelho de si mesmo, um animal que estava 
sendo preso numa humanização forjada, ou tenha apenas reconhecido nela outro animal, um outro de si mesmo; a menina ruiva, por sua vez, pode ter visto nele uma singularidade, um ser com algo a ser compartilhado ou comunicado, mas talvez possa ter visto, pela diferença que os unia, uma humanidade forjada ou uma animalidade domesticada; ou talvez ambos tenham apenas partilhado a tristeza, revolta, subversão por serem "ruivos em terra de morenos", animais em terra de humanos. Os três animais da cena abriram suas feridas e permitiram-se sentir, mas um deles foi mais "forte" e não olhou para trás nenhuma só vez ao sair: esse animal foi o cão. O cão, mesmo humanizado, não se deixa humanizar por completo, ele guarda latente sua animalidade, seu desejo não era o mesmo da menina, ele viu nela outro animal, ela viu nele sua animalidade domesticada, ambos viram o outro. A diferença desses seres torna-os singulares, aproxima-os entre familiaridades e estranhezas e também dobra, divide e emaranha em nós a suposta linha entre humanos e animais. A tentação desse conto chama-nos ao proibido, ao inapropriado, a algo que está fora da norma ou da convenção social, o desejo de ir além dos limites supostamente intransponíveis do eu e do outro.

Em quatro obras da série Animales familiares, da artista visual Ana Teresa Barboza, encontramos duas obras em que esse desejo, essa tentação de transpassar os limites que nos afastam do outro e da diferença são multiplicados; e, em outras duas obras, parecem ser transpostos pelo contágio, pelos afetos, pelos instintos, por um movimento de entrega ao desconhecido; ou possivelmente as duas alternativas passam-se nas quatro obras. Essas obras têm em comum, além de mostrarem outras relações entre os limites do humano e do animal, protagonistas humanas mulheres e animais selvagens, um lobo ou loba, uma leoa e um leão, animais dotados de força, magnetismo, liberdade e uma certa animalidade latente e nada abafada, que parecem provocar um movimento de atração nessas humanas. Ambas as relações entre esses limites do desconhecido não são necessariamente tranquilas ou tensas, mas se dão pela presença do outro, por deixar-se estar com esse outro e estabelecer com ele alguma comunicação ou um fazer em conjunto, mesmo que seja apenas um estar junto, fazerem-se presenças lado a lado. 
Imagem 2 - Ana Teresa Barboza. (sem título), 2012, da série Animales familiares. Bordado em tela, $(33 \times 39 \mathrm{~cm})$.

Imagem 3 - Teresa Barboza. (sem título), 2011, da série Animales familiares. Grafite e bordado em tela, $(70$ x $49 \mathrm{~cm})$.
Imagem 4 - Ana Teresa Barboza. (sem título), 2012, da série Animales familiares. Bordado em tela, $(33 \times 39 \mathrm{~cm})$.

Imagem 5 - Ana Teresa Barboza. (sem título), 2011, da série Animales familiares. Grafite e bordado em tela, $(70 \times 49 \mathrm{~cm})$.

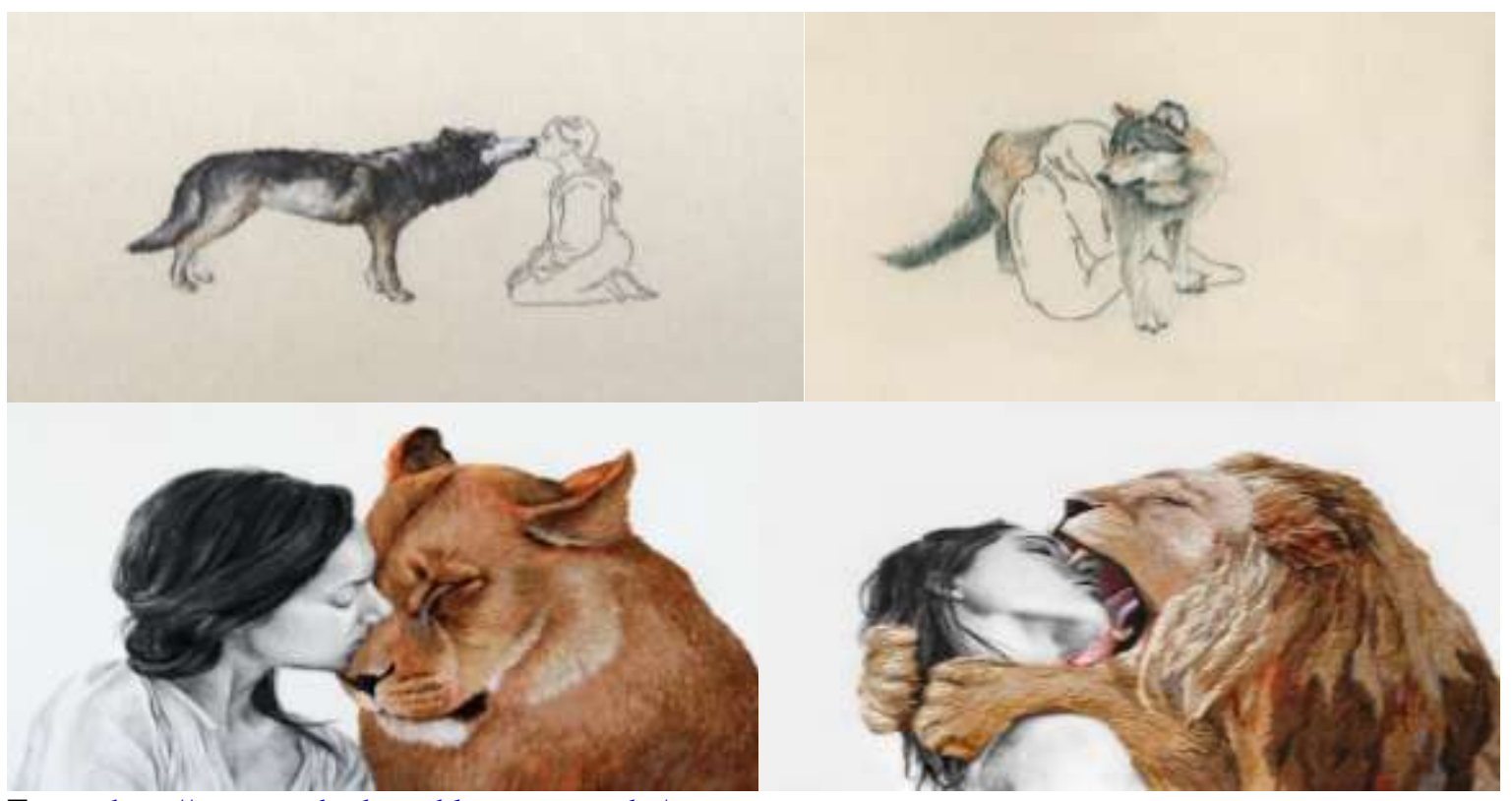

Fonte: http://anateresabarboza.blogspot.com.br/

Na primeira obra (Imagem 2), essas relações se estabelecem pelo olhar e pelo contato, com um lobo ou uma loba (na imagem não está determinado o gênero do animal, talvez por não ser necessária mais uma oposição entre binarismos) frente a frente com uma humana, mulher, fêmea. Na segunda obra (Imagem 5), as relações se estabelecem pelo contato, pelos sentidos, toque e olfato, com uma leoa entregando-se sem medo a uma humana, mulher, fêmea. Nas duas obras, parece estar em jogo uma comunicação e um estar junto que se cria por meio de outras sensibilidades e racionalidades, que perpassam os sentidos e afetos. Esses dois animais nomeados como feras parecem abrigar uma estranha docilidade e amorosidade que desconcerta o imaginário que os pinta como seres sanguinários e terríveis, que desconcerta os discursos que nos fazem temer essa animalidade latente. Mas essa animalidade doce e amigável pode, a qualquer momento, tragar-nos, levar-nos para dentro de si mesma e devorar nosso eu, humano e singular, fragmentando-o em múltiplos pedaços de nós mesmos. E, na mesma esteira, essa humanidade doce e amigável pode, a qualquer momento, domesticar ou humanizar esse eu, animal e singular, em um grupo plural e homogêneo. São duas imagens que parecem falar de uma metáfora para as relações entre o eu e os outros: por mais doces ou tensas que sejam essas relações, nunca voltaremos os mesmos, porém devemos ter a responsabilidade de estar junto a 
esses outros ao invés de mantê-los afastados num plural genérico ou capturá-los como um espelho de nós mesmos e não de nossa própria outridade. É nesse movimento de entregar-se ao outro, de, mesmo temendo ser capturado, arriscar-se a ser multiplicado ou talvez aniquilado, que quatro viventes (Imagens 4 e 6) compartilham da transposição de suas fronteiras e permitem-se estar junto, contagiar-se, experimentar e sentir o outro e a si mesmos nesse contato entre afetos, instintos, sentidos e alteridades.

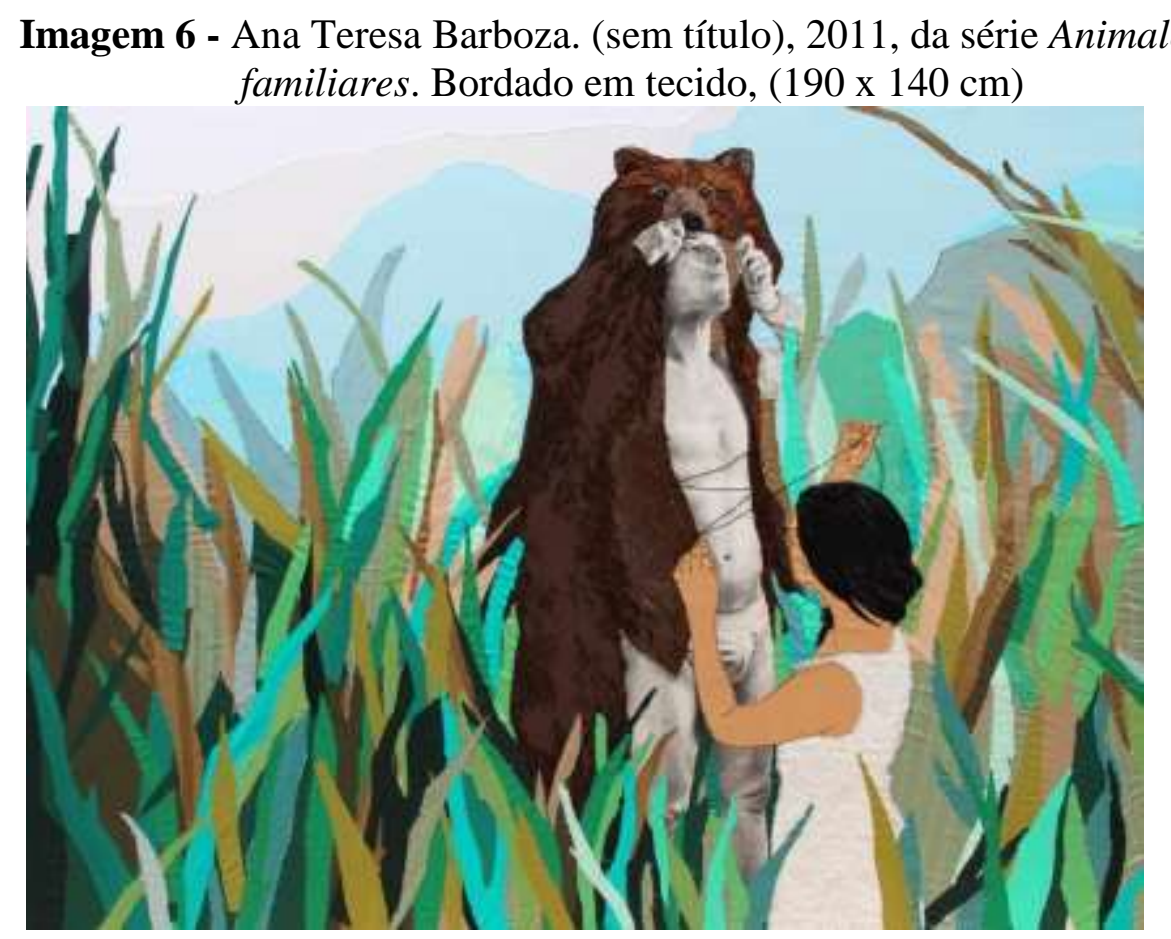

Fonte: http://anateresabarboza.blogspot.com.br/

Entretanto, outras relações com a animalidade também são possíveis, como nos mostra a obra sem título de Ana Teresa Barboza, da Série Animales familiares (2011). Na imagem, vemos quatro personagens: um humano macho; um urso morto; uma humana fêmea e a natureza. O humano está localizado acima da natureza e da humana, olhando também por cima e além delas, mas parece, de alguma forma, depender delas: ele não tem as cores, muito menos as "faculdades" de criar e dar vida a outros seres como elas têm. Ele está colocando sobre seus ombros uma pele de urso e parece estar apoiado em uma suposta superioridade ao olhar para cima, não parecendo conectar-se nem com a mulher nem com o que já foi esse animal em vida.

Mesmo nessa condição "superior", porém, ele depende dessa mulher e desse animal. Essa dependência pode ser analisada de diferentes formas: esse homem poderia estar buscando outras relações com a animalidade ou somente usando a força, poder e calor desse animal, bem como das "faculdades" dessa humana? Ele parece somente alcançar tal poder colocando-se acima da natureza e dessa humana fêmea que costura uma suposta animalidade nele - ou, quem 
sabe, um suposto poder desse animal? Essa relação estabelecida com a animalidade seria somente um modo de perpetuar uma lógica de dominação e subjugação, seja com os animais, seja com os “mais animalizados"? Parece-nos que aqui está em jogo uma outra lógica de relação com a animalidade, não como diferença e alteridade, mas de um eu que busca, na relação com o outro, incluí-lo em si, que busca, no outro animal e na mulher, mais dotada de animalidade, um caminho para tornar-se mais forte e mais soberano. Esse homem híbrido do animal parecenos que irá usar a força desses dois seres contra eles mesmos, perpetuando uma dominação do outro, uma relação baseada em receber algo em troca, uma relação ambígua e que ainda divide a animalidade em polos opostos: às vezes, ela pode ser entendida e diminuída como uma força cruel, a força dos selvagens e das feras, uma força tirânica e sanguinária, porém, quando necessário, o uso dessa força muda de figura e é entendida como coragem, bravura, valentia e potência.

Percebemos, nessa obra, outras possibilidades de relação à animalidade, que se valem da apropriação do outro, que, além de incluir, abafar e subjugar, torna o outro igual a si mesmo, torna o outro eu mesmo, talvez por não aceitar que essa suposta diferença também o habita. Essa relação de dominação e apropriação do outro e da diferença pode ser vista de outra forma na crônica Amor, de Lispector (1999, p. 373-375). A crônica remete às impressões da autora ao ver caminhar na rua um homem levando pela coleira, como se fosse um cão, um quati, um animal selvagem que fora domesticado, enganado e resignado a viver como um cão. O cão é um dos animais mais "humanizados" por nós, humanos, um animal que há muito tempo já foi selvagem, mas do qual foi tirado o direito de viver sua própria animalidade. Nós o ensinamos a depender de nossa segurança, alimento e afeto e, em troca, o obrigamos a cuidar de nós e de nossas casas, a sanar nossas carências afetivas, ou talvez uma carência de compartilhar certas relações com outros animais, dos quais nos afastamos pela crescente urbanização de nossa sociedade. O quati da história que fora submetido a ser cão já não sabia mais o que era, e o homem caminhava na rua como se estivesse protegendo um sonho, uma fantasia. Para não o perder, o homem que poderia livrá-lo dessa situação nunca irá lhe dizer quem ele realmente é. A autora coloca-se no lugar desse animal e imagina seus sentimentos e anseios por não saber quem é: "Eu sou pelo bicho e tomo partido das vítimas do amor ruim. Mas imploro ao quati que perdoe o homem e que perdoe com muito amor. Antes de abandoná-lo." (LISPECTOR, 1999, p. 375).

A escritora, em sua condição de humana, mas também de animal, consegue ao mesmo tempo estabelecer uma relação empática com o quati e com o homem que o aprisiona, uma relação de alteridade que está acima de bem e mal, justo e injusto, opressor e oprimido, uma 
relação talvez de responsabilidade incondicional com o outro, como nos propôs Derrida (2002, 2004, 2016). Não é uma tarefa fácil para nós, humanos, entender que muitas de nossas formas de amar tornam-se abusivas e aprisionantes, tal como fazemos com os animais. Ignoramos nossa própria animalidade, mas queremos usar a animalidade de outros seres em nosso benefício e sob o pretexto de um suposto amor. Como disse Lispector (1999), o homem adulterou a essência do ser daquele animal a fim de usá-lo. Ela percebe isso ao ver o homem com seu quati, mas não percebe a mesma relação que estabelece com os cães, quando afirma "Que carência é essa que faz você inventar um cachorro? E por que não um cachorro então? Pois se os cachorros existem?” (LISPECTOR, 1999, p. 374). Os cães não têm mais um habitat natural e não conseguem mais viver sozinhos em nossa sociedade altamente urbanizada, o processo de domesticação transformou a mente e o comportamento dos cães. Assim, se o quati pensava-se cachorro, o que pensa ser o cachorro? Eles pensam ser humanos ou nós somos seus semelhantes? Não sabemos a resposta, mas vamos tentar supor trazendo para a vida do cão o que a autora fez-nos perceber em relação ao quati. O cão, mesmo sentindo amor e gratidão pelos humanos, não percebe sua condição de aprisionamento, pois está vitalmente confuso. E quando souberem que lhes adulteramos a essência a fim de usá-los, será que nos perdoarão ou irão nos massacrar?

Talvez esse seja o medo e pavor da personagem presente na obra de Ana Teresa Barboza (Imagem 7), em que vemos uma mulher fechando os olhos com as mãos para não ver o que se passa ao seu lado: um cão na iminência de atacá-la. Não parece tratar-se de um simples ataque de defesa, mas de algo mais tenso, algo que toca profundamente a essência desses dois seres. 
Imagem 7 - Ana Teresa Barboza. (sem título), 2011, da série Animales familiares.

Bordado em tecido, $(33 \times 39 \mathrm{~cm})$

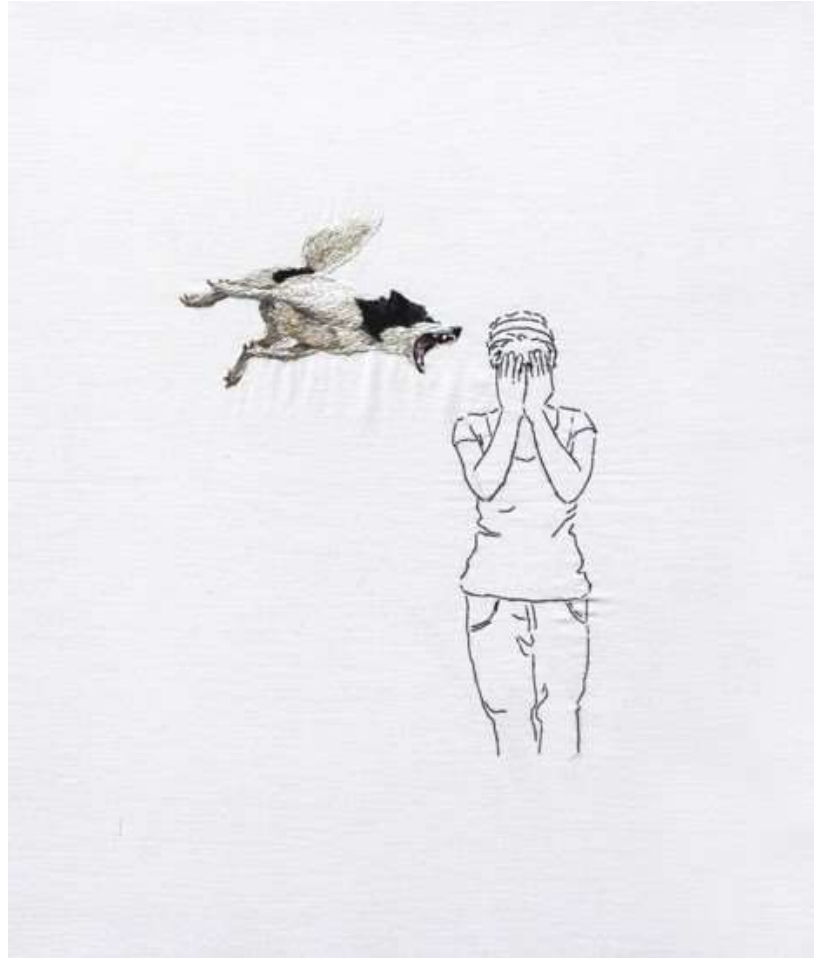

Fonte: http://anateresabarboza.blogspot.com.br/

Pensando a partir da crônica que trata da relação de um homem com seu quati, podemos supor que esse cão está reivindicando, com tamanho ódio, sua animalidade, sua essência animal e não humana. Mesmo se isso fosse possível, a domesticação dos cães não tem mais volta, porém podemos, para diminuir essa tensão, não humanizá-los, mas respeitar sua natureza, sua alteridade, ou seja, nós é que devemos nos "animalizar" para viver junto deles (LISPECTOR, 1999, p. 334) e, quem sabe, aprender mais sobre eles e nós mesmos nesse processo de “animalizar-se", aprender e criar outras relações entre as fronteiras do eu e do outro. Mudando nosso olhar, percebemos que o suposto medo da personagem de Barboza (2011) poderia nascer do medo de aceitar-se também animal, de animalizar-se. O medo dessa mulher não parte das reivindicações do cão, mas do que sua presença a faz enxergar e lembrar: seus "próprios instintos abafados", sua própria animalidade que é provocada ao ser confrontada e deixar-se ser vista pelo olhar desse animal, pois "quem se recusa à visão de um bicho está com medo de si próprio" (LISPECTOR, 1999, p. 334). Esse medo "provoca o lado animal que trazemos dentro de nós" (MACIEL, 2016, p. 13). Entregar-se à animalidade que nos habita pode gerar medos e tensões, mas pode fazer-nos perceber que, em nós, habitam muitos outros, muitas diferenças que podem movimentar relações singulares com os outros. 
Habitar nossa animalidade não necessariamente constrói-nos como um outro ser humano ou leva-nos a uma responsabilidade incondicional com outras alteridades, como vimos na obra de Ana Teresa Barboza (Imagem 7) e na história de Clarice Lispector (1999) sobre o homem e seu quati. Nessas obras, os humanos fazem uso de sua animalidade e da de outros como forma de poder, domesticação e aprisionamento de outras alteridades. Porém, habitando uma suposta humanidade soberana à animalidade e às outras formas de vida, há tantos séculos, não conseguimos criar seres humanos menos soberanos e antropocêntricos, muito menos relacionarmo-nos de outras formas com as alteridades do que não nos é semelhante. Talvez nós, educadores, possamos usar essas obras como ponto de partida para criar um tempo na escola em que os alunos possam suspender seu passado e sua herança, possam descobrir outras possibilidades de ser humano, possam ser artistas e poetas que se recriam pelo contato com palavras e imagens (como no caso das obras analisadas), que os levem a outras racionalidades sensíveis e racionais, outros contatos com o estranho e a diferença. Podemos, quem sabe, com nossas práticas pedagógicas, tornar nebulosas as fronteiras entre os supostos polos, podemos abrir caminhos para uma coexistência que não busque apagar as diferenças nem as fronteiras, mas reconstruir a alteridade para além do eu e do outro. Com a literatura e as artes visuais, podemos criar um tempo para os alunos habitarem sua animalidade e experienciarem a de outros seres. Com isso, os alunos (e docentes também) podem iniciar sua própria travessia a outras margens e fronteiras, estabelecendo outras relações nessas bordas, outras relações de alteridade na educação. É possível criar um tempo de animalidade em que podemos "perder" a "linguagem", suspender suas heranças, tirar "das coisas a camada de palavras", habitar a "calma profundidade do mistério" e viver na "latência das coisas" (LISPECTOR, 1992, p. 101-102) e dos seres. Não se trata somente de criar um tempo na escola para habitarmos nossa animalidade, mas uma outra forma de educação, que não parta somente de uma humanidade que nega sua animalidade e que acredita em uma única linha instransponível entre a humanidade e a animalidade.

Pensamos que as obras que apresentamos, por meio de sua poética e estética, levam-nos a experimentar relações com outras vidas, "impossíveis de sentir, de tocar, de perceber”, vidas fora de nós mesmos, sem alcance e capturas, vidas que nos provocam a ser e não estar, a arriscarmo-nos a pensar de outros modos e a partir de outras sensibilidades e linguagens (SKLIAR, 2014, p. 145-146). Essas outras vidas, seja a das humanas ou a dos animais, criadas pelas imagens, provocam-nos a ir junto delas nessa subversão dos limites e das normas, convocam-nos a despirmo-nos de certas convenções e normatizações, a comunicarmo-nos e estar juntos com o desconhecido, com a diferença. Para isso, é necessário suspender-se, 
“desobedecer a linguagem", estar disposto a não saber, sair de si mesmo, expor-se, "sentir em carne viva o passar dos desconhecidos" (SKLIAR, 2014, p. 150). Nesse estado de nudez, de suspensão, quem sabe, podemos despedaçar-nos de nós mesmos, de nossas certezas, heranças e multiplicarmo-nos em outros animais humanos que somos. Não se trata de concordar com o desconhecido e a diferença, mas de escutar, de deixar-se ser olhado e questionado por eles e por esses outros de nós mesmos, antes ignorados ou não pensados. Essas outras relações de comunicação e contato com os outros, movimentadas pelas obras analisadas, provocam-nos a deixar, de uma vez, de sustentar as dualidades. Assim, as obras analisadas tencionam-nos a perceber a relação com o outro como diferença e não como semelhança ou uma representação de nós mesmos; desse modo, viver nas fronteiras do outro, da diferença, da animalidade é um modo de repensar o que é humano e suas relações com os tantos outros, configurando, mais uma vez, a potência formativa das relações entre artes visuais, literatura e animalidade. Porém, para tal movimento, para tal estado de suspensão, de relação e contágio pelas obras, é necessário ter disposição e tempo. [...] Se tivéssemos tempo para dar-nos tempo, se em vez de julgar apreciássemos, escutássemos, fizéssemos coisas em comum, não haveria nenhuma necessidade de nomear os outros como diferentes. [...] (SKLIAR, 2014, p. 158).

\section{Considerações finais}

Depois de todas essas questões, como pensar a relação entre alteridade e educação? Como criar um tempo de formação pela animalidade na escola, considerando possíveis poéticas da animalidade? Se não há tempo, as normatizações e heranças de um único limite inacessível entre humanos e animais assumem as horas da escola, das práticas pedagógicas, da vida. Sem tempo, não aprenderemos a desobedecer certas linguagens e acessar outras, sem tempo, não há como estabelecer uma comunicação sensível ou uma responsabilidade incondicional com alteridades radicais que nos escapam, sem tempo, não há descoberta de outros usos da razão. A questão do tempo mostra-se ser essencial para as relações entre animalidade, alteridades e educação que buscamos estabelecer neste artigo.

Sem tempo, não há modos de habitar as linhas entre alteridades. Somente na suspensão de um tempo antropocêntrico, de um tempo de medos e desconfianças, podemos perceber as sutilezas das produções estéticas ligadas às poéticas da animalidade e também ver e ser visto pelos outros. Será que algum dia nós, humanos, conseguiremos estabelecer outras relações de alteridade? Será que conseguiremos viver nas bordas e nas fronteiras, a partir de linhas de diferenças que nos unem e aproximam? Talvez as respostas estejam nas obras com as quais 
dialogamos, pois elas desobedecem a sequência linear, única e instransponível que supostamente se estabelece entre humanos e animais, entre o eu e os outros. Em suas poéticas e estéticas, não nos acariciam ou inflam nosso eu, mas antes mostram nossas garras, nossa animalidade latente, expõem nossas feridas e fazem-nas sangrar, num processo de "cura". Nas obras, os animais desobedecem a nossa linguagem e forçam-nos a encontrar outras formas de comunicação, no olhar, no silêncio, no contato, no estar lado a lado, no sentir. Elas removemnos de nós mesmos, “daquilo que nós somos, daquilo que de nós se sabe: o idêntico a si mesmo não provoca nada que não seja sandice e saturação" (SKLIAR, 2014, p. 128).

As provocações ético-estéticas das obras analisadas não nos ensinam a habitar nossa animalidade, nem a transpassar os limites antropocêntricos do humano, mas, tal como a filosofia de Derrida (2002), oferecem-nos significados abertos, nus, que não precisam estar atrelados aos limites filosóficos entre humanidade e animalidade, humano e animal, ofertam-nos possibilidades de olhar e sentir de outros modos. São imagens e escritas não resolvidas, que nos movimentam e deslocam, pois deixam traços, rastros de animalidade a serem lidos, vistos, sentidos e multiplicados por outros. Em nossa multiplicação, essas provocações são experiências de alteridades, de animalidades que dão vozes, imagens e pensamentos a uma “razão animal” (MACIEL, 2016, p. 92), que pode ser nossa ou de outros animais. Dessa outra forma de racionalidade, dessa animalidade vista como um modo de formação humana, podemos extrair infinitos conhecimentos poéticos, estéticos, éticos e políticos sobre nós mesmos, sobre os outros e sobre o mundo. Clarice Lispector e Ana Teresa Barboza, e nosso olhar atento às suas produções, fornecem-nos alguns caminhos e possíveis pistas. Resta saber se a escola e o campo educacional podem abrir-se às potências estéticas das poéticas da animalidade.

\footnotetext{
${ }^{1}$ Este artigo apresenta discussões desenvolvidas em: MORAIS, Tathiana Jaeger. Uma criação poética da animalidade: artes visuais, literatura e outras relações de alteridade na educação. UFRGS, 2018. Dissertação (Mestrado em Educação) Faculdade de Educação, Universidade Federal do Rio Grande do Sul, Porto Alegre, 2018.

${ }^{2}$ No final da década de 2000, cresceram as problematizações sobre a questão animal nos campos culturais e teóricos, surgindo, assim, um novo campo investigativo, chamado animal studies - ou estudos animais. Esse campo inter/transdisciplinar desafia os discursos que estabeleceram uma suposta linha única, imutável e intransponível entre o que conhecemos por humanos e animais e, com tais discursos, buscaram justificativas para subjugar os animais, esses seres que sempre foram definidos por algo que lhes falta, seja a falta de razão, de linguagem, de compromisso moral etc. (PRIKLADNICKI, 2015, p. 14). Michael Lundblad (2009), "defende o termo 'estudos da animalidade' (animality studies) por considerar o termo 'estudos animais' muito limitador, muito facilmente confundido com um chamado pela advocacia universal pelos animais de verdade" (PRIKLADNICKI, 2015, p. 18). Neste trabalho, apoiamo-nos, de certo modo, na perspectiva de Lundblad (2009), pois acreditamos que estudar as questões que envolvem a animalidade não consiste somente em debruçar-se sobre as relações políticas e éticas entre animais-humanos e não humanos, mas também entre animais-humanos e seus pares.

${ }^{3}$ Destacamos alguns pensadores importantes que nos ajudam a multiplicar o que entendemos por animalidade, humanidade, humano e animais, tais como: Friedrich Nietzsche; Jacques Derrida; Gilles Deleuze e Félix Guattari; Michel Foucault; Giorgio Agamben; Tim Ingold; Dominique Lestel; Frans de Waal; Gabriel Giorgi; Steve Baker; Giovanni Aloi; Peter Singer; Gary L. Francione e Maria Esther Maciel.
} 


\section{Referências}

AGAMBEN, Giorgio. $O$ aberto. $O$ homem e o animal. Tradução: André Dias e Ana Bigotte Vieira. Lisboa: Edições 70, 2013.

DERRIDA, Jacques. A besta e o soberano (Seminário) - v. 1 (2001-2002). Rio de Janeiro: Vila Verita, 2016.

DERRIDA, Jacques. De que amanhã. Rio de Janeiro: Jorge Zahar, 2004.

DERRIDA, Jacques. O animal que logo sou (A seguir). São Paulo: Editora: UNESP, 2002. Disponível em: https://repositorio-aberto.up.pt/handle/10216/75492. Acesso em: 20 out. 2016.

FOUCAULT, Michel. Literatura e Pintura, Música e Cinema. In: FOUCAULT, Michel. Ditos \&escritos III. Rio de Janeiro: Forense Universitária, 2009.

GIORGI, Gabriel. Formas comuns - animalidade, literatura, biopolítica. Rio de Janeiro: Rocco, 2016.

LISPECTOR, Clarice. A descoberta do mundo. Rio de Janeiro. Rocco, 1999.

LISPECTOR, Clarice. A maça no escuro. Rio de Janeiro: Francisco Alves, 1992.

LISPECTOR, Clarice. A legião estrangeira. São Paulo: Ática, 1987.

LISPECTOR, Clarice. Perto do coração selvagem. Rio de Janeiro: Rocco, 1998.

LUNDBLAD, Michael. From animal to animality studies. PMLA, New York, v. 124, n. 2, 2009.

MACIEL, Maria Esther. Literatura e animalidade. Rio de Janeiro: Civilização Brasileira, 2016.

MORAIS, Tathiana Jaeger. Uma criação poética da animalidade: artes visuais, literatura e outras relações de alteridade na educação. 2018. Dissertação (Mestrado em Educação) Faculdade de Educação, Universidade Federal do Rio Grande do Sul, Porto Alegre, 2018.

PRIKLADNICKI, Fábio. Reinscrevendo a responsabilidade: figurações da alteridade entre o humano e o animal. 2015. Tese. (Doutorado em Letras) - Instituto de Letras, Universidade Federal do Rio Grande do Sul, Porto Alegre, 2015. Disponível em:

http://hdl.handle.net/10183/131624. Acesso em: 10 dez. 2016.

SKLIAR, Carlos. Desobedecer a linguagem: educar. Belo Horizonte: Autêntica, 2014. 